\title{
Managing high-priced biologic agents: challenges and potential solutions
}

\author{
Meng Li, ScM, PhD, and Kai Yeung, PharmD, PhD
}

Ulcerative colitis is an inflammatory bowel disease that affects the inner lining of the colon and rectum. ${ }^{1}$ Patients with ulcerative colitis have significant impairment in physical and mental health, social functioning, and pain, as well as loss of productivity. ${ }^{2-4}$ The Institute for Clinical and Economic Review (ICER) synthesized the evidence on the efficacy,

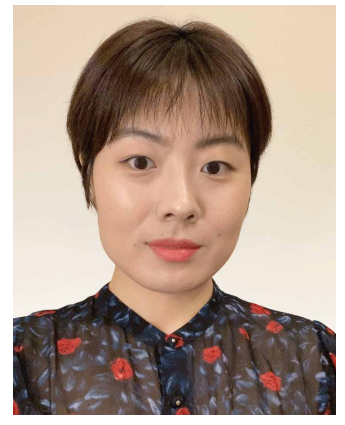

Meng Li, ScM, PhD

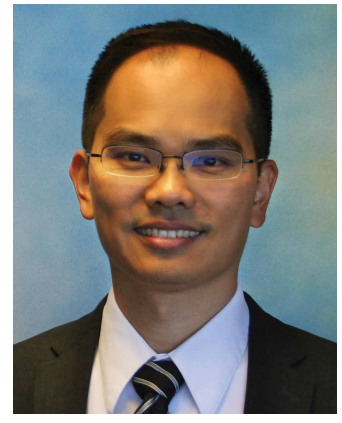

Kai Yeung, PharmD, PhD safety, and costs of 8 targeted immune modulators (TIMs) for the treatment of patients with moderate to severe ulcerative colitis that does not respond to conventional treatments (immunosuppressants and systemic corticosteroids). It found that each of the 8 TIMs demonstrated greater efficacy than conventional treatments in least 1 study outcome. ${ }^{5}$

While these biologic agents may confer health benefits to patients with ulcerative colitis, there are also substantial challenges for health care payers in managing their use in this disease. First, the prices of TIMs are high. The net price per year of maintenance therapy for TIMs range from approximately $\$ 14,000$ for infliximab and its biosimilars to $\$ 91,609$ for ustekinumab, while the net prices for mercaptopurine and azathioprine-2 conventional therapies-are $\$ 2,314$ and $\$ 493$ per year, respectively. ${ }^{5}$ Consequently, except for infliximab and its biosimilars, TIMs are far from cost-effective, with the cost per quality-adjusted life-year (QALY) ranging between $\$ 300,000$ and $\$ 1,800,000$, even after accounting for potential productivity gains. ${ }^{5}$

A second challenge is that traditional managed care tools such as high copayment or coinsurance tiers and step therapy have limitations for managing the costs and use of TIMs. Cost sharing imposes substantial financial burden on patients who are already bearing great clinical burden and may also be circumvented by copay coupons. ${ }^{6}$ Further, utilization management tools do not adequately address a key clinical feature of ulcerative colitis: treatment heterogeneity. Patients often lose response to their medications or develop intolerable side effects. In a disease with heterogeneous and evolving response to treatments, step therapy limits the ability of patients and physicians to

\author{
Author affiliations \\ Meng Li, ScM, PhD, Department of Health \\ Services Research, University of Texas MD \\ Anderson Cancer Center, Houston. \\ Kai Yeung, PharmD, PhD, Kaiser \\ Permanente Washington Health \\ Research Institute, Seattle, and \\ Kaiser Permanente Bernard J. Tyson \\ School of Medicine, Pasadena, CA. \\ AUTHOR CORRESPONDENCE: \\ Kai Yeung, 206.287.2063; \\ Kai.Yeung@kp.org
}

J Manag Care Spec Pharm. 2021;27(3):411-14

Copyright $\odot 2021$, Academy of Managed Care Pharmacy. All rights reserved.

make timely treatment choices based on the characteristics and preferences of individual patients, which may ultimately affect treatment outcomes. Consequently, ulcerative colitis patient groups have frequently cited step therapy as a barrier to timely and appropriate care. ${ }^{7}$ In a recent survey of 2,600 patients with inflammatory bowel disease, $40 \%$ had been subjected to step therapy, among whom nearly $60 \%$ were required to fail 2 or more drugs before gaining access to the originally prescribed medications. $^{7}$ 
A third challenge is that there is a limited evidence base for the comparative effectiveness of individual TIMs and treatment pathways for the treatment of ulcerative colitis, which further restricts the ability of payers to apply utilization management tools in a clinically nuanced fashion. Only 1 trial directly compares a TIM head to head with another TIM. Further, there are concerns regarding a lack of evidence for other outcomes that are important to patients with ulcerative colitis. Finally, the ICER report highlighted "essentially a complete absence of robust comparative evidence" regarding treatment effectiveness for particular subpopulations.

What can payers do to advance the shared mission of ensuring timely access to high-quality, cost-effective, and affordable medicines that are aligned with patient preferences? ${ }^{8}$ Several innovative value-based pricing solutions have garnered interest..$^{9,10}$ Indication-based pricing sets different prices for different indications for the same drug based on indication-specific efficacy and safety. ${ }^{10-12}$ For example, several of the TIMs can also be used to treat rheumatoid arthritis, and their incremental costs per QALY gained are more favorable when used for rheumatoid arthritis-approximately $\$ 200,000$ per QALY. ${ }^{13}$

While it is difficult to make direct comparison of costeffectiveness across disease areas with different standards of care, the substantially different cost-effectiveness ratios suggest that indication-specific pricing is needed and that the list prices of TIMs should be discounted more when used for ulcerative colitis (by $40 \%$ and $60 \%$ for infliximab and its biosimilars and between $70 \%$ and $90 \%$ for other TIMs) in order to achieve value parity with its use in rheumatoid arthritis. ${ }^{5,13}$ Further, lowering the prices through indication-based pricing would weaken the need for payers to apply high cost sharing in order to steer medication utilization and defray costs. When the price is right, payers can lower cost sharing to help patients adhere to treatment. Of course, a major unresolved challenge is how payers and manufacturers can arrive at a mutually agreeable indication-based price.

Another limitation of indication-based pricing is that it draws on efficacy data from pivotal clinical trials at the time of a drug's market entry to estimate a drug's value and its indication-based price. This may differ from the actual experiences of a health plan's patient population, especially for heterogenous diseases such as ulcerative colitis. Performance-based risk-sharing arrangements are a method for payers to manage this uncertainty in real-world outcomes by sharing some of the financial risk associated with the uncertainty with the manufacturers. . $^{12,14,15}$

An outcomes guarantee contract is a form of risksharing arrangement in which outcome targets, with a reimbursement level, are agreed upon at the outset. If the drug fails to meet the outcome targets, the manufacturer provides financial adjustments (i.e., rebate or refund) to the payers. ${ }^{10,16}$ An outcomes guarantee contract arrives at a value-based price and resolves uncertainty by tracking the clinical and economic outcomes of patients and aligns net payment at the end of the contract period with the drug's value in the real world.

However, outcomes guarantee contracts are not without challenges. They are difficult to negotiate and require significant payer and provider infrastructure that can track outcomes of individual patients. Many drugs do not have easily measurable outcomes. In addition, patients often switch health plans, making it difficult to determine longterm results. For some drugs, how they are prescribed and used may affect their effectiveness, but pharmaceutical companies have no control over these aspects, making risk sharing difficult. ${ }^{17}$ Finally, the significant administrative costs from negotiation, data collection, monitoring, and adjudication could offset any potential savings.

Despite these challenges, there is growing uptake of indication-based pricing and outcomes guarantees. Among U.S. payers, approximately $60 \%$ have executed at least 1 outcomes guarantee contract in 2019-more than doubling the percentage in 2017-with nearly one third reporting that they had more than 5 outcomes guarantee contracts. ${ }^{18}$ One notable example is an agreement in 2018 between Harvard Pilgrim and Spark Therapeutics on voretigene neparvovec, an $\$ 850,000$ one-time gene therapy for a form of retinal dystrophy. Both short-term (30-90 days) efficacy and longer-term (30 months) durability are assessed, and Spark Therapeutics will pay rebates if patient outcomes fail to meet a specified threshold..$^{19,20}$

Among public payers, Colorado, Michigan, and Oklahoma have received approval from the Centers for Medicare \& Medicaid Services (CMS) to enter outcomes guarantee agreements with manufacturers for their state Medicaid programs. ${ }^{21}$ Combining elements of indication-based pricing and outcomes guarantees, Express Scripts launched its Inflammatory Conditions Care Value Program in 2016, with indication-specific formulary management and refunds for early discontinuation of therapy. ${ }^{22}$ Participating plan sponsors will receive refunds of up to $\$ 6,000$ if a patient discontinues any preferred anti-inflammatory medication within the first 90 days.

Another potential solution to managing TIMs is the promotion of biosimilars. In the ICER report, the price of infliximab and its biosimilars is substantially lower than the other biologics. However, the overall uptake of biosimilars in the United States has been slow compared with other developed countries. ${ }^{23,24}$ One contributing factor may be the 
lack of payer coverage of biosimilars. A recent analysis found that $14 \%$ of the 535 coverage decisions issued by health plans granted the biosimilar preferred coverage, 33\% nonpreferred coverage, and $53 \%$ on par coverage. ${ }^{25}$ Yet, the costs of bringing a biosimilar to market is high-at least 10-fold greater than the costs of bringing a generic small molecule to market. ${ }^{26}$ Hence, biosimilar manufacturers need greater assurance that their candidates would be taken up by health plans after approval by the U.S. Food and Drug Administration.

The lack of preferential coverage of biosimilars among payers may partly be due to the reference biologic manufacturers' strategies to secure long-term contracts or bundled rebate contracts across multiple drugs that make it financially more attractive for an individual payer to prefer the reference biologic. However, it is the credible threat of biosimilar competition that brings reference biologic manufacturers to the negotiating table, and without appropriate market signals, biosimilar development will be slowed. Recognizing this need, CMS has begun to promote the use of biosimilars over the reference biologic in Medicare Advantage plans. ${ }^{27}$ Other payers should similarly consider incentivizing biosimilar development, marketing, and uptake by granting preferred coverage status.

In many ways, TIMs for the treatment of ulcerative colitis illustrate the contemporary challenges that managed care payers face in managing biologic agents across many therapeutic classes: high prices, moderately average value, inadequate evidence on comparative effectiveness, and substantial heterogeneity in treatment response. Such challenges are likely to continue as high-priced biologic agents continue to consume larger proportions of pharmacy spending. ${ }^{28}$ Traditional managed care tools impose real patient burdens. Fortunately, payers have several innovative pricing tools that can bring payment closer to the value of a drug in the real world. Payers should consider such tools in negotiations and coverage decisions.

\section{DISCLOSURES}

No funding was received for the writing of this commentary. The authors report no conflicts of interest.

\section{REFERENCES}

1. Ungaro R, Mehandru S, Allen PB, Peyrin-Biroulet L, Colombel JF. Ulcerative colitis. Lancet. 2017;389(10080):1756-70.

2. Constantin JA-O, Atanasov P, Wirth D, Borsi A. Indirect costs associated with ulcerative colitis: a systematic literature review of real-world data. BMC Gastroenterol. 2019;19(1):179.

3. Kawalec P, Malinowski KP. Indirect health costs in ulcerative colitis and Crohn's disease: a systematic review and meta-analysis. Expert Rev Pharmacoecon Outcomes Res. 2015;15(2):253-66.

4. Yarlas A, Rubin DT, Panés J, et al. Burden of ulcerative colitis on functioning and well-being: a systematic literature review of the SF-36® Health Survey. J Crohns Colitis. 2018;12(5):600-09.

5. Ollendorf DA, Bloudek L, Carlson JJ, et al. Targeted immune modulators for ulcerative colitis: effectiveness and value. Final evidence report and meeting summary. Institute for Clinical and Economic Review. October 16, 2020. Accessed February 4, 2021. https://icer.org/ wp-content/uploads/2020/08/ICER_ UC_Final_Evidence_Report_101620.pdf

6. Yeung K, Barthold D, Dusetzina SB, Basu A. Patient and plan spending after state specialty-drug out-of-pocket spending caps. N Engl J Med. 2020;383(6):558-66.

7. Crohn's \& Colitis Foundation. Step therapy: an obstacle course to optimal health. 2020. Accessed February 4, 2021. https://www.crohnscolitisfoundation. org/get-involved/be-an-advocate/ steptherapy
8. Academy of Managed Care Pharmacy. About AMCP. 2020. Accessed February 4, 2021. https://www.amcp.org/about/ about-AMCP

9. Bach PB, Pearson SD. Payer and policy maker steps to support value-based pricing for drugs. JAMA. 2015;314(23):2503-04.

10. Kaltenboeck A, Bach PB. Value-based pricing for drugs: theme and variations. JAMA. 2018;319(21):2165-66.

11. Bach PB. Indication-specific pricing for cancer drugs. JAMA. 2014;312(16):1629-30.

12. Yeung K, Li M, Carlson JJ. Using performance-based risk-sharing arrangements to address uncertainty in indication-based pricing. J Manag Care Spec Pharm. 2017;23(10):1010-15. doi: 10.18553/jmcp.2017.23.10.1010

13. Ollendorf DA, Campbell J, Whittington $\mathrm{MD}$, et al. Targeted immune modulators for rheumatoid arthritis: effectiveness \& value. Evidence report. Institute for Clinical and Economic Review. April 7, 2017. Accessed February 4, 2021. http:// icerorg.wpengine.com/wp-content/ uploads/2020/10/NE_CEPAC_RA_ Evidence Report FINAL 040717.pdf

14. Yu JS, Chin L, Oh J, Farias J.

Performance-based risk-sharing arrangements for pharmaceutical products in the United States: a systematic review. J Manag Care Spec Pharm. 2017;23(10): 1028-40. doi: 10.18553/jmcp.2017.23.10.1028

15. Carlson JJ, Sullivan SD, Garrison LP, Neumann PJ, Veenstra DL. Linking payment to health outcomes: a taxonomy and examination of performance-based reimbursement schemes between healthcare payers and manufacturers. Health Policy (New York). 2010;96(3):179-90.

16. Carlson JJ, Garrison LP, Sullivan SD. Paying for outcomes: innovative coverage and reimbursement schemes for pharmaceuticals. J Manag Care Spec Pharm. 2009;15(8):683-87. doi: 10.18553/ jmcp.2009.15.8.683

17. Garrison LP, Carlson JJ, Bajaj PS, et al. Private sector risk-sharing agreements in the United States: trends, barriers, and prospects. Am J Manag Care. 2015;21(9):632-40. 
18. Butler S, Linnehan JE. More than half of health plans use outcomes-based contracts. Avalere. October 1, 2019. Accessed February 4, 2021. https://avalere.com/ press-releases/more-than-half-of-healthplans-use-outcomes-based-contracts

19. Spark Therapeutics. Spark Therapeutics announces first-of-theirkind programs to improve patient access to LUXTURNATM (voretigene neparvovec-rzyl), a one-time gene therapy treatment. January 3, 2018. Accessed February 4, 2021. https://sparktx.com/ press releases/spark-therapeuticsannounces-first-of-their-kind-programsto-improve-patient-access-to-luxturnavoretigene-neparvovec-rzyl-a-one-timegene-therapy-treatment/

20. Harvard Pilgrim Health Care. Harvard Pilgrim is first health plan to directly negotiate outcomes-based agreement for groundbreaking gene therapy. January 3, 2018. Accessed February 4, 2021. https://www.harvardpilgrim. org/public/news-detail?nt=HPH_ News C\&nid $=1471914707173$
21. Meyer H. As a cure for high drug prices, outcomes-based deals aren't delivering yet. Modern Healthcare. 2019. Accessed February 4, 2021. https://www. modernhealthcare.com/insurance/ cure-high-drug-prices-outcomes-baseddeals-arent-delivering-yet

22. Express Scripts. Express Scripts launches Inflammatory Conditions Care Value Program(SM), making America's costliest medication class more affordable. September 8, 2016. Accessed February 4, 2021. https:// www.prnewswire.com/news-releases/ express-scripts-launches-inflammatoryconditions-care-value-programsm-making-americas-costliest-medication-classmore-affordable-300324538.html

23. Winegarden W. Incenting competition to reduce drug spending: the biosimilar opportunity. July 2019. Accessed February 4, 2021. https://medecon. org/wp-content/uploads/2019/07/ BiosimilarsCompetition_F.pdf

24. Zhai MZ, Sarpatwari A, Kesselheim AS. Why are biosimilars not living up to their promise in the U.S.? AMA J Ethics. 2019;21(8):E668-78.
25. Chambers JD, Lai RC, Margaretos NM, Panzer AD, Cohen JT, Neumann PJ. Coverage for biosimilars vs reference products among US commercial health plans. JAMA. 2020;323(19):1972-73. doi: 10.1001/jama.2020.2229

26. Federal Trade Comission. Emerging health care issues: follow-on biologic drug competition. June 2009. Accessed February 4, 2021. https://www.ftc. gov/sites/default/files/documents/ reports/emerging-health-care-issuesfollow-biologic-drug-competitionfederal-trade-commission-report/ p083901biologicsreport.pdf

27. Verma S. Increasing access to generics and biosimilars in Medicare. Medicare Agent News. February 25, 2020. Accessed February 4, 2021. http://medicareagentnews.blogspot.com/2020/02/ increasing-access-to-generics-and.html

28. The IQVIA Institute. Medicine use and spending in the U.S. A review of 2017 and outlook to 2022. The IQVIA Institute. April 19, 2018. Accessed February 4, 2021. https://www.iqvia.com/ insights/the-iqvia-institute/reports/ medicine-use-and-spending-in-the-usreview-of-2017-outlook-to-2022 